九州大学学術情報リポジトリ

Kyushu University Institutional Repository

\title{
APOE and CYP2E1 polymorphisms, alcohol consumption, and Parkinson's disease in a Japanese population
}

\section{Kiyohara, Chikako}

Department of Preventive Medicine, Graduate School of Medical Sciences, Kyushu University

Miyake, Yoshihiro

Department of Public Health, Faculty of Medicine, Fukuoka University

Koyanagi, Midori

Department of Cell Biology, Faculty of Medicine, Fukuoka University

Fuj imoto, Takah i ro

Department of Cell Biology, Faculty of Medicine, Fukuoka University

他

http://hdl. hand le. net/2324/25598

出版情報 : Journal of Neural Transmission. 118 (9)，pp.1335-1344，2011-09. Springer Vienna バージョン:

権利関係: (C) Springer-Verlag 2011 
$A P O E$ and CYP2E1 polymorphisms, alcohol consumption, and Parkinson's disease in a Japanese population

Chikako Kiyohara, Yoshihiro Miyake, Midori Koyanagi, Takahiro Fujimoto, Senji

Shirasawa, Keiko Tanaka, Wakaba Fukushima, Satoshi Sasaki, Yoshio Tsuboi, Tatsuo

Yamada, Tomoko Oeda, Takami Miki, Nobutoshi Kawamura, Nobutaka Sakae, Hidenao

Fukuyama, Yoshio Hirota, Masaki Nagai for the Fukuoka Kinki Parkinson's Disease

Study Group*

C. Kiyohara (Email)

Department of Preventive Medicine, Graduate School of Medical Sciences, Kyushu University, Fukuoka, Japan

e-mail: chikako@phealth.med.kyushu-u.ac.jp

Tel: +81 (0)926426112 Fax: +81 (0)926426115

Y. Miyake, K. Tanaka

Department of Public Health, Faculty of Medicine, Fukuoka University, Fukuoka, Japan

M. Koyanagi, T. Fujimoto, S. Shirasawa

Department of Cell Biology, Faculty of Medicine, Fukuoka University, Fukuoka, Japan

W. Fukushima, Y. Hirota

Department of Public Health, Osaka City University Graduate School of Medicine, Osaka, Japan

\section{S. Sasaki}

Department of Social and Preventive Epidemiology, School of Public Health, The University of Tokyo, Tokyo, Japan

Y. Tsuboi, T. Yamada

Department of Neurology, Faculty of Medicine, Fukuoka University, Fukuoka, Japan 
Kiyohara et al. -2-

T. Oeda

Clinical Research Institute and Department of Neurology, Utano National Hospital, Kyoto, Japan

T. Miki

Department of Geriatrics and Neurology, Osaka City University Graduate School of Medicine, Osaka, Japan

N. Kawamura, N. Sakae

Department of Neurology, Neurological Institute, Graduate School of Medical Sciences, Kyushu University, Fukuoka, Japan

H. Fukuyama

Human Brain Research Center, Kyoto University Graduate School of Medicine, Kyoto, Japan

M. Nagai

Department of Public Health, Saitama Medical University Faculty of Medicine, Saitama, Japan.

Other members of the Study Group are listed in the Appendix.

Concise title: $A P O E$ and $C Y P 2 E 1$ polymorphisms and PD risk 
Kiyohara et al. -3-

Abstract Apolipoprotein E (APOE) is associated with increased oxidative stress, which is caused by reactive oxygen species (ROS). Enhanced cytochrome P450 2E1 (CYP2E1) activity may also increase formation of neurotoxins such as ROS. As Parkinson's disease (PD) is a neurodegenerative disorder, both the APOE and CYP2E1 genes that are involved in neurodegeneration by oxidative stress may be associated with PD risk. We investigated the relationship of the APOE and CYP2E1 rs2864987 polymorphisms and PD risk with special attention to the interaction with alcohol consumption among 238 patients with PD and 296 controls in a Japanese population. The frequencies of the $\varepsilon 2, \varepsilon$ 3and $\varepsilon 4$ alleles of the $A P O E$ polymorphism among controls were $3.72,86.7$ and $9.63 \%$, respectively. As compared with the APOE $\varepsilon 3 / \varepsilon 3$ genotype, the $2 / \varepsilon 4$ genotype was associated with an increased risk of PD (adjusted odds ratio $(\mathrm{OR})=9.50,95 \%$ (confidence interval $) \mathrm{CI}=1.12-80.6) . \quad$ The presence of the $\varepsilon 3$ allele was associated with a decreased risk of PD. Meanwhile, CYP2E1 rs2864987 was not associated with PD risk. Although CYP2E1 is involved in the metabolism of alcohol, there was no evidence of interaction between alcohol consumption and CYP2E1 rs2864987. Our results suggested that the APOE polymorphism might play an important role in PD susceptibility in our Japanese population. Future studies involving larger control and case populations and better alcohol consumption histories will undoubtedly lead to a more thorough understanding of the role of polymorphisms of genes related to the generation of ROS in PD development.

Keywords apolipoprotein E; cytochrome P450 2E1; interaction; Parkinson's disease; case-control study; Japanese population 


\section{Introduction}

Oxidative and nitrosative stress caused by accumulation of reactive oxygen (ROS) and nitrogen species can affect different pathways and contribute to the pathogenesis of Parkinson's disease (PD) (Jenner 2003; Tsang and Chung 2009; Seet et al. 2010) Generation of ROS is an inevitable outcome of oxygen dependent respiration. Cytochrome P450 2E1 (CYP2E1) is hypothesized to be important for the pathophysiology of PD, either by its production of ROS or by its ability to detoxify putative neurotoxins (Fahn and Cohen 1992; Jimenez-Lopez and Cederbaum 2005). Similarly, apolipoprotein E (APOE) is also associated with increased oxidative stress (Jofre-Monseny et al. 2008) caused by generation of ROS.

Genetic susceptibility, which is associated with production or metabolism of endogenous and exogenous neurotoxins, is implicated in the pathophysiology of PD (Riedl et al. 1998). APOE is responsible for clearance of the $\beta$-amyloid plaques that impair the nervous system (Bales et al. 2002). The APOE gene has three common alleles, $\varepsilon$ 2, $\varepsilon 3$ and $\varepsilon$ 4, which determine the protein isoforms E2, E3 and E4, respectively, and yield six possible genotypes, $\varepsilon 2 / \varepsilon 2, \varepsilon 2 / \varepsilon 3, \varepsilon 2 / \varepsilon 4, \varepsilon 3 / \varepsilon 3, \varepsilon 3 / \varepsilon 4$ and $\varepsilon 4 / \varepsilon 4 . \quad$ E2 and E3 clear plaques 20 times more efficiently than E4 (Mahley and Rall 2000). E3 seems to be the normal isoform in all known functions, while E4 and E2 can each be dysfunctional (Mahley and Rall 2000). The $\varepsilon 4$ allele is widely accepted to be a risk factor for Alzheimer's disease (Corder et al. 1993; Welsh-Bohmer et al. 1997). Because PD and Alzheimer's disease share common features, some of their genetic determinants may be the same or similar. The $\varepsilon 4$ allele may play a harmful role in PD development. However, associations between the APOE 
Kiyohara et al. -5-

polymorphism and PD have yielded mixed results. Several studies and a meta-analysis showed that the $\varepsilon 2$ allele is associated with an increased risk of PD (The French Parkinson's Disease Genetics Study Group 1997; Harhangi et al. 2000; Huang et al. 2004), while other studies and another meta-analysis showed that the $\varepsilon 4$ allele is associated with an increased risk of PD (Arai et al. 1994; Harhangi et al. 2000; Li et al. 2004; Huang et al. 2006). Therefore, both the $\varepsilon 2$ and the $\varepsilon 4$ alleles are hypothesized to play a deleterious role in PD development.

CYP2E1 is distributed heterogenously among the brain areas (Hansson et al. 1990). A number of polymorphisms in the coding and non-coding regions of $C Y P 2 E 1$ have been reported. No significant associations between these polymorphisms and PD risk have been reported (Bandmann et al. 1997; Wang et al. 2000; Wu et al. 2002; Singh et al. 2008). However, it is hypothesized that the genotype involved in a higher catalytic activity may be associated with an increased risk of PD.

Studying gene-environment interactions in relation to PD risk may be valuable because positive findings would clearly implicate disease-causing exposures, clarify PD etiology, and point to environmental modifications for disease prevention. As it is not clear at present whether the CYP2E1 rs2864987 (adjacent to rs6413432) polymorphism can change CYP2E1 activity, no studies have been undertaken regarding the rs 2864987 polymorphism and PD. However, the possibility that this polymorphism is associated with PD risk cannot be ruled out. This study aimed to determine the main effect of polymorphisms of genes related to the generation of ROS (APOE and CYP2E1 rs2864987) and interaction between the CYP2E1 rs2864987 polymorphism and alcohol consumption on PD risk in a Japanese population. 


\section{Materials and Methods}

Study subjects

PD patients were recruited at three university hospitals and one national hospital in Fukuoka Prefecture, a metropolitan area of Kyushu Island in southern Japan, and at three university hospitals, three national hospitals and one municipal hospital in Osaka, Kyoto, and Wakayama Prefectures. Eligible (prevalent) cases were patients who were within six years of the onset of PD and who presented at one of the 11 collaborating hospitals between April 1, 2006 and March 31, 2008. The mean duration ( \pm SD) of PD was 38.8 (16.7) months. During the same period, hospital controls, without a previous diagnosis of a neurodegenerative disease, were recruited from other departments of three of the 11 collaborating hospitals because hospital controls are more motivated and are more easily accessible for obtaining DNA samples. It is unlikely that our hospital controls had a genetic predisposition for PD. Controls were not, individually or in larger groups, matched to cases. Details of the study subjects have been documented elsewhere (Miyake et al. 2010).

Subjects (611 total; 240 PD patients and 371 controls) agreed to donate buccal samples. Data on smoking and pesticide use were insufficient for two cases and one control. In total, 238 cases and 370 controls were enrolled in this study. The research protocol was approved by the ethics committees of the 11 collaborating universities/hospitals, and all subjects signed informed consent.

Genetic analysis 
Kiyohara et al. -7-

Genomic DNA was extracted from buccal samples. Genetic determinations were made blinded to PD status. TaqMan® SNP Genotyping Assays purchased from Applied Biosystems (Foster City, CA, USA) were used for the following (gene, SNP, assay ID): $A P O E$, rs7412, C_904973_10; APOE, rs429358, and C_3084793_20. The genetic variants of CYP2E1 rs2864987 were assayed using the Custom TaqMan® SNP Genotyping Assay purchased from Applied Biosystems.

Statistical analysis

Degree of freedom (df) for Hardy-Weinberg equilibrium (HWE) was calculated as the difference between the number of genotypes and the number of alleles. Each SNP APOE rs7412, APOE rs429358 (on $3 \mathrm{df}$ ) and CYP2E1 rs2864987 (on $1 \mathrm{df}$ ), as expected, demonstrated HWE according to chi-square tests among controls only. We hypothesized that the less active allele of $C Y P 2 E 1$ and the common allele $\varepsilon 3$ of $A P O E$ would be associated with decreased risk of PD. To test this hypothesis, an unconditional logistic model constructed for each polymorphism was used to predict PD status. Then, corresponding models were constructed to adjust for the following possible confounding factors: age (years), sex, region of residence, smoking status (ever vs. never), alcohol consumption [long-term consumption of alcoholic beverages (continuing consuming for $\geq 50$ years, which is a cutoff point at the 90 th percentile of the distribution among the control and case groups combined) vs. short-term consumption of alcoholic beverages (continuing consuming for $<50$ years)], pesticide exposure at work (ever used any insecticide, herbicide, or fungicide vs. never used). Other models were constructed that collapsed genotype into both copies of the more 
Kiyohara et al. -8-

common active version vs. carrying one or two copies of the less active allele. If alcohol consumption increased risk for the more active allele of $C Y P 2 E 1$, interaction terms were included in subsequent logistic models (multiplicative scale). Three measures for biologic interaction (additive scale), namely the relative excess risk due to interaction (RERI), attributable proportion (AP) and synergy index (SI), were also calculated. The additive interaction measures were calculated in the Excel sheet provided by Andersson et al. (Andersson et al. 2005) using regression coefficients and covariances. If there was no interaction, RERI and AP are equal to zero, and SI and the multiplicative interaction term are equal to one.

All statistical analyses were implemented in STATA Version 10.1. Statistical significance was declared for $\mathrm{P}<0.05$ (two-sided).

\section{Results}

As controls were not selected to match PD patients on age, there was a significant difference in age between $238 \mathrm{PD}$ patients and 370 controls $(\mathrm{P}=0.008$, data not shown). Age is a potential risk factor for the development of PD. To avoid a significant difference in age affecting a big part of the results, subjects under 60 years of age $(n=74)$ were excluded from this study. Finally, 238 patients with PD and 296 controls were enrolled in the study. The distributions of selected characteristics among the study subjects are summarized in Table 1. Age, sex ratio, pesticide use, status of alcohol drinking and region of residence did not differ significantly between cases and controls. The PD patients were less likely to report a history of smoking compared to the control subjects $(\mathrm{P}<0.0001)$. 
Kiyohara et al. -9-

The distributions of APOE and CYP2E1 rs2864987 polymorphisms among cases and controls are shown in Table 2. The frequencies of the $\varepsilon 2 / \varepsilon 2, \varepsilon 2 / \varepsilon 3, \varepsilon 2 / \varepsilon 4$, $\varepsilon 3 / \varepsilon 3, \varepsilon 3 / \varepsilon 4$ and $\varepsilon 4 / \varepsilon 4$ genotypes of the APOE polymorphism among controls were $0,7.09,0.34,73.6,18.9,0 \%$, respectively. There was a statistical difference in genotypic distribution $(\mathrm{P}=0.042)$ and the $\varepsilon 3$ carrier status $(\mathrm{P}=0.007)$ between the PD cases and controls. No significant differences in allele frequency or specific allele carrier status were observed in any other comparisons. The APOE polymorphism did not deviate from HWE in controls $\left(\mathrm{P}_{\mathrm{HWE}}=0.177\right.$, data not shown).

As for the CYP2E1 rs2864987 polymorphism, the frequencies of the TT, TC and CC genotypes among controls were 45.3, 45.6, and 9.12, respectively (Table 2). No significant differences in genotype distribution or allele frequency were observed. The genotype distribution of $C Y P 2 E 1$ rs2864987 was also consistent with HWE in controls $\left(\mathrm{P}_{\mathrm{HWE}}=0.471\right.$, data not shown $)$.

As shown in Table 3, the $\varepsilon 2 / \varepsilon 4$ genotype was associated with an increased risk of $\mathrm{PD}$ compared with the common $\varepsilon 3 / \varepsilon 3$ genotype (adjusted $\mathrm{OR}=9.50,95 \% \mathrm{CI}=$ 1.12 - 80.6). To elucidate the role of each allele, stratified analyses by allele status were performed. For the $\varepsilon 3$ allele carriers, subjects with at least one $\varepsilon 3$ allele had a decreased risk of PD. In other words, subjects with either $\varepsilon 2 / \varepsilon 2, \varepsilon 2 / \varepsilon 4$ or $\varepsilon 4 / \varepsilon 4$ had an increased risk of PD. The $\varepsilon 3$ allele appeared to act in a dominant mode in this study. Generally, the reference category is the absence of exposure (risk factor). As the $\varepsilon$ 3-containing genotypes were included in both the reference and exposure categories, the impact of $\varepsilon 2$ and $\varepsilon 4$ allele statuses on PD risk was attenuated in the analysis of specific allele carrier status. 
Kiyohara et al. -10-

There was no clear evidence of association between CYP2E1 rs2864987 and PD risk (Table 3). There was no difference in OR between the TC and CC genotypes. The $\mathrm{C}$ allele appeared to act in a dominant fashion in this study. Based on the associations between $C Y P 2 E 1$ rs 2864987 and PD, we designated the allele presumed to increase the risk of PD as the "at-risk" allele (T allele). The "at-risk" allele can be assumed to be a higher catalytic activity (more ROS production).

As CYP2E1 enzyme is important in ethanol metabolism, the effects of CYP2E1 rs2864987 may be modified by alcohol consumption. We assessed interactions between CYP2E1 rs2864987 and alcohol consumption (Table 4). As the C allele of CYP2E1 rs2864987 behaves in a dominant fashion, subjects with at least one $\mathrm{C}$ allele were bundled in one group for subsequent analysis. Long-term alcohol consumption was nonsignificantly associated with increased risk of PD (adjusted OR $=1.43,95 \% \mathrm{CI}$ $=0.82-2.50 ;$ data not shown). Long-term alcohol consumers with the TT ("at-risk") genotype (adjusted $\mathrm{OR}=2.24,95 \% \mathrm{CI}=1.01-4.95$ ) had a significantly higher risk of PD than short-term alcohol consumers with at least one $\mathrm{C}$ allele (reference).

Long-term alcohol consumers with at least one $\mathrm{C}$ allele and short-term alcohol consumers with the TT genotype faced approximately 1.3-fold increased risk of lung cancer. However, no multiplicative interaction of alcohol consumption and the CYP2E1 rs2864987 polymorphism with PD was observed. Assessment of additive (biologic) interaction measures was also carried out. Three additive interaction measures between the CYP2E1 rs2864987 genotypes and alcohol consumption did not reach statistical significance. Four interaction measures (multiplicative interaction, RERI, AP and S) were also far from statistically significant. 
Kiyohara et al. -11-

There was no interaction between the APOE polymorphism and CYP2E1 rs2864987 (data not shown).

\section{Discussion}

The APOE and CYP2E1 rs2864987 polymorphisms were determined in $238 \mathrm{PD}$ cases and 296 controls. In this study, the frequencies of the $\varepsilon 2$, $\varepsilon$ 3and $\varepsilon 4$ alleles of the $A P O E$ polymorphism among controls were $3.72,86.7$ and $9.63 \%$, respectively. These values were similar to those reported in Japanese populations (Eto et al. 1986; Kobori et al. 1988; Ou et al. 1998; Yoshida et al. 2009). It has been reported that the prevalences of the $\varepsilon 2, \varepsilon 3$ and $\varepsilon 4$ alleles are similar between Caucasians and Asians (Thakkinstian et al. 2006). In most populations, at least $50 \%$ of the population has two copies of the $\varepsilon 3$ allele ( $\varepsilon 3 / \varepsilon 3$ genotype) and at least $20 \%$ carry at least one copy of the $\varepsilon 4$ allele $(\varepsilon 2 / \varepsilon 4, \varepsilon 3 / \varepsilon 4$, or $\varepsilon 4 / \varepsilon 4)$. The $\varepsilon 2$ allele appears to be absent in some populations living in arctic regions, but, in most populations, at least 5\% carry one or two copies $(\varepsilon 2 / \varepsilon 2, \varepsilon 2 / \varepsilon 3$, or $\varepsilon 2 / \varepsilon 4)$ (Gerdes et al. 1996). Conversely, little data is available related to the allelic (genotypic) distribution of the CYP2E1 rs2864987 polymorphism.

In the present study, the $\varepsilon 2 / \varepsilon 4$ genotype of the $A P O E$ polymorphism was also significantly related to $\mathrm{PD}$ risk $(\mathrm{OR}=9.50,95 \% \mathrm{CI}=1.12-80.6) . \quad$ APOE is localized to the cytoplasm of cortical neurons (Han et al. 1994). Oxidative stress results from excess ROS overwhelming any endogenous antioxidant protection. Oxidative damage markers are systemically elevated in PD (Seet et al. 2010), which may give clues about the relation of oxidative damage to the onset and progression of 
$\mathrm{PD}$, as the APOE gene may be involved in the generation of ROS (Fahn and Cohen 1992; Jofre-Monseny et al. 2008). One Chinese study (Tang et al. 2002) found a significant association between the $\varepsilon 2 / \varepsilon 4$ genotype and PD risk $(\mathrm{OR}=6.35,95 \% \mathrm{CI}=$ 1.08 - 37.22). However, our result should be interpreted with caution because it might be a false positive association because the number of subjects with the $\varepsilon 2 / \varepsilon 4$ genotype was small. A family-based association analysis found that the $\varepsilon 4$ allele significantly increased PD risk $(\mathrm{OR}=1.8,95 \% \mathrm{CI}=1.1-3.38)(\mathrm{Li}$ et al. 2004). Recently, a genome-wide linkage study concluded that the $\varepsilon 4$ allele is responsible for the linkage peak in this region, and that this allele is a modest risk factor for PD (Martinez et al. 2005). A meta-analysis by Huang et al. also showed that the $\varepsilon 4$ allele is associated with dementia in $\mathrm{PD}(\mathrm{OR}=1.7,95 \% \mathrm{CI}=1.0-2.8)$. Unlike the protective role of the $\varepsilon 2$ allele in Alzheimer's disease (Farrer et al. 1997), one French study reported a significantly higher frequency of the $\varepsilon 2$ allele in PD cases than controls $(\mathrm{OR}=2.45,95 \% \mathrm{CI}=1.15-5.21)$ (The French Parkinson's Disease Genetics Study Group 1997). Another meta-analysis by Huang et al. also showed that the $\varepsilon 2$ allele is associated with an increased risk of sporadic $\mathrm{PD}(\mathrm{OR}=1.20,95 \% \mathrm{CI}=1.02$ 1.42) (Huang et al. 2004). Both the $\varepsilon 2(\mathrm{OR}=5.6,95 \% \mathrm{CI}=2.0-15.2)$ and the $\varepsilon 4$ $(\mathrm{OR}=3.6,95 \% \mathrm{CI}=1.3-9.9)$ alleles increased the risk of PD with dementia (Harhangi et al. 2000). Although many studies on the association between the APOE polymorphism and PD showed null results (Egensperger et al. 1996; Bon et al. 1999; Oliveri et al. 1999; Maraganore et al. 2000; Eerola et al. 2002; Parsian et al. 2002; Tang et al. 2002; Blazquez et al. 2006; Papapetropoulos et al. 2007), it is biologically plausible that the $\varepsilon 4$ allele is associated with an increased risk of PD because 
Kiyohara et al. -13-

$\beta$-amyloid plaques and tau protein-associated tangles are increased in the brains of individuals with the $\varepsilon 4$ allele (Schmechel et al. 1993). The mechanism by which the presence of the $\varepsilon 2$ allele increases PD risk is not clear. The number of subjects without the $\varepsilon 3$ allele was small in this study, due to the extremely high frequency of the $\varepsilon 3$ allele. There was not a significant association between the $\varepsilon 4 / \varepsilon 4$ or $\varepsilon 2 / \varepsilon 2$ genotype and PD risk, which may be due to the small sample of patients with the $\varepsilon 4 / \varepsilon 4$ or $\varepsilon 2 / \varepsilon 2$ genotype. At present, we could not determine whether the $\varepsilon 2$ or $\varepsilon 4$ allele may increase PD risk. The possibility that the absence of the $\varepsilon 3$ allele increased PD risk cannot be ruled out. In fact, the absence of the $\varepsilon 3$ allele was significantly associated with increased risk of PD (adjusted $\mathrm{OR}=13.0,95 \% \mathrm{CI}=1.61-104.1$ ). Regardless, the association between the $\varepsilon 2 / \varepsilon 4$ genotype and PD risk was suggested among Asian populations but not among Caucasian populations. Similarly, the impact of the $\varepsilon 4$ allele on risk for Alzheimer's disease was stronger in Japanese than in Caucasians (Farrer et al. 1997). These ethnic differences may reflect different gene-environment interactions, gene-gene interactions, or different linkages to the polymorphisms determining PD risk.

We did not detect an association between the CYP2E1 rs2864987 polymorphism and PD. CYP2E1 is localized in neurons in the substantia nigra but not in glial cells (Watts et al. 1998). Like with the APOE gene, the CYP2E1 gene may be involved in the generation of ROS (Fahn and Cohen 1992; Jimenez-Lopez and Cederbaum 2005). Two polymorphisms [Pst I (rs3813867) and Rsa I (rs2031920)], which are located in the 5'-flanking region in a putative binding region for transcription factor HNF-1 (Hayashi et al. 1991), are in complete linkage disequilibrium (Stephens et al. 1994). The minor 
allele (c2 allele) that lacks the Rsa I restriction site is associated with higher transcriptional activity, protein levels, and enzyme activity of the CYP2E1 protein than the more common wild-type allele (c1 allele) (Hayashi et al. 1991; Watanabe et al. 1994). Carriers of the $\mathrm{c} 2 / \mathrm{c} 2$ genotype might have an increased ability to activate endogenous or exogenous neurotoxins and may therefore develop an increased risk of PD. The Dra I polymorphism (rs6413432) is caused by a base pair change in intron 6 of the CYP2E1 gene. The Dra I polymorphism is classified into the following three genotypes: heterozygotes (CD) and two forms of homozygotes (CC and DD). Recently, a significant association between the Dra I polymorphism and peripheral nerve injuries was found (Zhang et al. 2006). Individuals with the CC genotype had a significantly higher risk of peripheral nerve damage compared with those with the DD genotype $(\mathrm{OR}=5.58,95 \% \mathrm{CI}=1.32-23.65)$ after $\mathrm{n}$-hexane exposure. The CC genotype may be linked to a higher CYP2E1 activity. The 96-bp insertion polymorphism is associated with transcriptional activity (Nomura et al. 2003). The Rsa I and 96-bp insertion polymorphisms were in almost complete linkage disequilibrium in a Japanese population (Morita et al. 2009). These CYP2E1 polymorphisms, with the exception of the rs2070676 (intron 7) polymorphism (Shahabi et al. 2009), were also not associated with PD (Bandmann et al. 1997; Wang et al. 2000; Wu et al. 2002; Singh et al. 2008; Shahabi et al. 2009).

In this study, long-term drinking nonsignificantly increased risk for PD. CYP2E1 metabolizes and activates many toxicological substrates, including ethanol, to more reactive products. As acetaldehyde, the primary metabolite of ethanol, is known to be a neurotoxin, it is biologically plausible that alcohol consumption may increase 
Kiyohara et al. -15-

PD risk. However, no clear link between total alcohol consumption and PD has been observed in most studies. Furthermore, a protective effect on PD risk has been suggested for alcohol consumption. A meta-analysis showed that alcohol consumption was significantly associated with a decreased risk of PD (summary OR among 13 case-control studies $=0.81,95 \% \mathrm{CI}=0.70-0.92$; summary OR among 4 cohorts studies $=0.73,95 \% \mathrm{CI}=0.57-0.92)($ Ishihara and Brayne 2005). These results may be biased due to residual confounding by cigarette smoking because there is a strong relationship between cigarette smoking and alcohol consumption and between cigarette smoking and PD risk. Or, the effects of alcohol on PD risk may vary by race/ethnicity. We evaluated the interaction between the CYP2E1 rs2864987 polymorphism and alcohol consumption (Table 4). It is widely accepted that PD develops based on the interaction of environmental factors in a genetically predisposed individual. Studying gene-environment interactions in relation to risk for PD may be valuable because positive findings would clearly implicate substrates with which the gene interacts as disease-causing exposures, clarify PD etiology, and point to environmental modifications for disease prevention. Alcohol consumers (suspected high risk population in this study) with the "at-risk" genotype TT may be more susceptible to PD than expected from the independent effects of the two (alcohol drinking and genetic) separate factors. A gene-environment interaction was suggested, with the combined "at-risk" genotype and long-term alcohol consumption conferring significantly higher risk $(\mathrm{OR}=2.24,95 \% \mathrm{CI}=1.01-4.95)$, compared with at least one $\mathrm{C}$ allele and short-term alcohol consumption in the present study. However, all interaction measures (multiplicative interaction, RERI, AP and SI) were far from statistically 
Kiyohara et al. -16-

significant. A mechanistic study of the neurotoxic compounds in our environment/lifestyle habits that serve as a substrate for the CYP2E1 enzyme may lead to better understanding of the role of the CYP2E1 polymorphisms in PD development. Additional epidemiological studies are also warranted to determine the alcohol-CYP2E1 polymorphism interactions, although our results suggest that the CYP2E1 polymorphism may not modify the association of alcohol consumption with PD risk.

A strength of this study is that cases were identified using strict diagnostic criteria, thus minimizing disease misclassification. We also designed this study with extensive data collection based on comprehensive literature review, allowing us to adjust for several potential confounders. Adjustment was made for extensive information on potential non-dietary and dietary confounding factors.

Several limitations of this study also warrant mention. First, this study may have included a bias due to the self-reporting of alcohol consumption. Consequently, the possibility of inaccurate exposure data and resulting misclassification bias should be considered when interpreting our findings. Second, recall bias is a potential limitation of case-control studies. As risk factors for PD are poorly characterized, study subjects have few systematic preconceived ideas regarding their disease etiology. Any recall bias was likely to be non-differential, given the many pesticides reported, the complex temporal pattern of their use, and the fact that subjects were not informed of the study hypotheses. Third, as the general Japanese population has a high prevalence of minor *2 allele of aldehyde dehydrogenase $2(A L D H 2)$ rs671 polymorphism (Yin et al. 2007) resulting in an inactive form that reduces the metabolism of acetaldehyde formed from ethanol, there is a possibility that the $A L D H 2$ rs671 polymorphism may modify the 
association between the $C Y P 2 E 1$ polymorphism and PD risk. It is possible that individuals with a combination of the TT genotype of CYP2E1 rs2864987 and the *2 allele of $A L D H 2$ rs671 polymorphisms may have a higher risk for ethanol induced damage leading to the development of PD. Further research on interactions between alcohol and genes involved in alcohol metabolism is warranted.

In conclusion, our results suggest that the $A P O E$ polymorphism plays an important role in PD susceptibility in our Japanese population. To the best of our knowledge, this is the first report on the main effect of the CYP2E1 rs2864987 polymorphism and the interaction between the CYP2E1 rs2864987 polymorphism and alcohol consumption. Long-term alcohol consumers with the TT genotype had a significantly higher risk of PD than short-term alcohol consumers with at least one C allele although our study does not provide evidence of interaction between the CYP2E1 rs2864987 polymorphism and alcohol consumption. Future mechanistic studies are needed to verify the functional significance of the CYP2E1 rs2864987 polymorphism. Also, additional epidemiological studies are warranted to determine the alcohol drinking-CYP2E1 rs2864987 polymorphism. In order to confirm our findings, future studies involving larger control and case populations and better alcohol consumption histories will undoubtedly lead to a more thorough understanding of the role of ROS-generating polymorphisms in PD development.

Acknowledgements This work was supported in part by Health and Labour Sciences Research Grants, Research on Intractable Diseases, and the Research Committee on 
Kiyohara et al. -18-

Epidemiology of Intractable Diseases from the Ministry of Health, Labour, and Welfare, Japan.

\section{Appendix}

Other members of the Fukuoka Kinki Parkinson's Disease Study Group are as follows: Yasuhiko Baba and Tomonori Kobayashi (Department of Neurology, Faculty of Medicine, Fukuoka University); Hideyuki Sawada, Eiji Mizuta, and Nagako Murase (Clinical Research Institute and Department of Neurology, Utano National Hospital); Tsuyoshi Tsutada and Hiroyuki Shimada (Department of Geriatrics and Neurology, Osaka City University Graduate School of Medicine); Jun-ichi Kira (Department of Neurology, Neurological Institute, Graduate School of Medical Sciences, Kyushu University); Tameko Kihira and Tomoyoshi Kondo (Department of Neurology, Wakayama Medical University); Hidekazu Tomimoto (Department of Neurology, Kyoto University Graduate School of Medicine); Takayuki Taniwaki (Division of Respirology, Neurology, and Rheumatology, Department of Medicine, Kurume University School of Medicine); Hiroshi Sugiyama and Sonoyo Yoshida (Department of Neurology, Minami-Kyoto National Hospital); Harutoshi Fujimura and Tomoko Saito (Department of Neurology, Toneyama National Hospital); Kyoko Saida and Junko Fujitake (Department of Neurology, Kyoto City Hospital); Naoki Fujii (Department of Neurology, Neuro-Muscular Center, National Omuta Hospital); Masatoshi Naito and Jun Arimizu (Department of Orthopaedic Surgery, Faculty of Medicine, Fukuoka University); Takashi Nakagawa, Hirofumi Harada, and Takayuki Sueta (Department of Otorhinolaryngology, Faculty of Medicine, Fukuoka University); Toshihiro Kikuta and 
Kiyohara et al. -19-

George Umemoto (Department of Oral and Maxillofacial Surgery, Faculty of Medicine, Fukuoka University); Eiichi Uchio and Hironori Migita (Department of Ophthalmology, Faculty of Medicine, Fukuoka University); Kenichi Kazuki, Yoichi Ito, and Hiroyoshi Iwaki (Department of Orthopaedic Surgery, Osaka City University Graduate School of Medicine); Kunihiko Siraki and Shinsuke Ataka (Department of Ophthalmology and Visual Sciences, Osaka City University Graduate School of Medicine); Hideo Yaname and Rie Tochino (Department of Otolaryngology and Head and Neck Surgery, Osaka City University Graduate School of Medicine); Teruichi Harada (Department of Plastic and Reconstructive Surgery, Osaka City University Graduate School of Medicine); Yasushi Iwashita, Motoyuki Shimizu, Kenji Seki, and Keiji Ando (Department of Orthopedic Surgery, Utano National Hospital).

\section{References}

Andersson T, Alfredsson L, Kallberg H, Zdravkovic S, Ahlbom A (2005) Calculating measures of biological interaction. Eur J Epidemiol 20:575-579

Arai H, Muramatsu T, Higuchi S, Sasaki H, Trojanowski JQ (1994) Apolipoprotein E gene in Parkinson's disease with or without dementia. Lancet 344:889

Bales KR, Dodart JC, DeMattos RB, Holtzman DM, Paul SM (2002) Apolipoprotein E, amyloid, and Alzheimer disease. Mol Interv 2:363-375, 339

Bandmann O, Vaughan J, Holmans P, Marsden CD, Wood NW (1997) Association of slow acetylator genotype for $\mathrm{N}$-acetyltransferase 2 with familial Parkinson's disease. Lancet 350:1136-1139

Blazquez L, Otaegui D, Saenz A, Paisan-Ruiz C, Emparanza JI, Ruiz-Martinez J, 
Kiyohara et al. -20-

Moreno F, Marti-Masso JF, Lopez de Munain A (2006) Apolipoprotein E epsilon4 allele in familial and sporadic Parkinson's disease. Neurosci Lett 406:235-239

Bon MA, Jansen Steur EN, de Vos RA, Vermes I (1999) Neurogenetic correlates of Parkinson's disease: apolipoprotein-E and cytochrome P450 2D6 genetic polymorphism. Neurosci Lett 266:149-151

Corder EH, Saunders AM, Strittmatter WJ, Schmechel DE, Gaskell PC, Small GW, Roses AD, Haines JL, Pericak-Vance MA (1993) Gene dose of apolipoprotein E type 4 allele and the risk of Alzheimer's disease in late onset families. Science 261:921-923

Eerola J, Launes J, Hellstrom O, Tienari PJ (2002) Apolipoprotein E (APOE), PARKIN and catechol-O-methyltransferase (COMT) genes and susceptibility to sporadic Parkinson's disease in Finland. Neurosci Lett 330:296-298

Egensperger R, Bancher C, Kosel S, Jellinger K, Mehraein P, Graeber MB (1996) The apolipoprotein E epsilon 4 allele in Parkinson's disease with Alzheimer lesions. Biochem Biophys Res Commun 224:484-486

Eto M, Watanabe K, Ishii K (1986) Reciprocal effects of apolipoprotein E alleles (epsilon 2 and epsilon 4) on plasma lipid levels in normolipidemic subjects. Clin Genet 29:477-484

Fahn S, Cohen G (1992) The oxidant stress hypothesis in Parkinson's disease: evidence supporting it. Ann Neurol 32:804-812

Farrer LA, Cupples LA, Haines JL, Hyman B, Kukull WA, Mayeux R, Myers RH, Pericak-Vance MA, Risch N, van Duijn CM (1997) Effects of age, sex, and 
ethnicity on the association between apolipoprotein E genotype and Alzheimer disease. A meta-analysis. APOE and Alzheimer Disease Meta Analysis Consortium. JAMA 278:1349-1356

Gerdes LU, Gerdes C, Hansen PS, Klausen IC, Faergeman O, Dyerberg J (1996) The apolipoprotein E polymorphism in Greenland Inuit in its global perspective. Hum Genet 98:546-550

Han SH, Einstein G, Weisgraber KH, Strittmatter WJ, Saunders AM, Pericak-Vance M, Roses AD, Schmechel DE (1994) Apolipoprotein E is localized to the cytoplasm of human cortical neurons: a light and electron microscopic study. J Neuropathol Exp Neurol 53:535-544

Hansson T, Tindberg N, Ingelman-Sundberg M, Kohler C (1990) Regional distribution of ethanol-inducible cytochrome P450 IIE1 in the rat central nervous system. Neuroscience 34:451-463

Harhangi BS, de Rijk MC, van Duijn CM, Van Broeckhoven C, Hofman A, Breteler MM (2000) APOE and the risk of PD with or without dementia in a population-based study. Neurology 54:1272-1276

Hayashi S, Watanabe J, Kawajiri K (1991) Genetic polymorphisms in the 5'-flanking region change transcriptional regulation of the human cytochrome P450IIE1 gene. J Biochem 110:559-565

Huang X, Chen P, Kaufer DI, Troster AI, Poole C (2006) Apolipoprotein E and dementia in Parkinson disease: a meta-analysis. Arch Neurol 63:189-193

Huang X, Chen PC, Poole C (2004) APOE-[epsilon]2 allele associated with higher prevalence of sporadic Parkinson disease. Neurology 62:2198-2202 
Kiyohara et al. -22-

Ishihara L, Brayne C (2005) A systematic review of nutritional risk factors of Parkinson's disease. Nutr Res Rev 18:259-282

Jenner P (2003) Oxidative stress in Parkinson's disease. Ann Neurol 53 Suppl 3:S26-36; discussion S36-28

Jimenez-Lopez JM, Cederbaum AI (2005) CYP2E1-dependent oxidative stress and toxicity: role in ethanol-induced liver injury. Expert Opin Drug Metab Toxicol $1: 671-685$

Jofre-Monseny L, Minihane AM, Rimbach G (2008) Impact of apoE genotype on oxidative stress, inflammation and disease risk. Mol Nutr Food Res 52:131-145

Kobori S, Nakamura N, Uzawa H, Shichiri M (1988) Influence of apolipoprotein E polymorphism on plasma lipid and apolipoprotein levels, and clinical characteristics of type III hyperlipoproteinemia due to apolipoprotein E phenotype E2/2 in Japan. Atherosclerosis 69:81-88

Li YJ, Hauser MA, Scott WK, Martin ER, Booze MW, Qin XJ, Walter JW, Nance MA, Hubble JP, Koller WC, Pahwa R, Stern MB, Hiner BC, Jankovic J, Goetz CG, Small GW, Mastaglia F, Haines JL, Pericak-Vance MA, Vance JM (2004) Apolipoprotein E controls the risk and age at onset of Parkinson disease. Neurology 62:2005-2009

Mahley RW, Rall SC, Jr. (2000) Apolipoprotein E: far more than a lipid transport protein. Annu Rev Genomics Hum Genet 1:507-537

Maraganore DM, Farrer MJ, Hardy JA, McDonnell SK, Schaid DJ, Rocca WA (2000) Case-control study of debrisoquine 4-hydroxylase, $\mathrm{N}$-acetyltransferase 2, and apolipoprotein E gene polymorphisms in Parkinson's disease. Mov Disord 
Kiyohara et al. -23-

$15: 714-719$

Martinez M, Brice A, Vaughan JR, Zimprich A, Breteler MM, Meco G, Filla A, Farrer MJ, Betard C, Singleton A, Hardy J, De Michele G, Bonifati V, Oostra BA, Gasser T, Wood NW, Durr A (2005) Apolipoprotein E4 is probably responsible for the chromosome 19 linkage peak for Parkinson's disease. Am J Med Genet B Neuropsychiatr Genet 136B:72-74

Miyake Y, Sasaki S, Tanaka K, Fukushima W, Kiyohara C, Tsuboi Y, Yamada T, Oeda T, Miki T, Kawamura N, Sakae N, Fukuyama H, Hirota Y, Nagai M (2010) Dietary fat intake and risk of Parkinson's disease: a case-control study in Japan. J Neurol Sci 288:117-122

Morita M, Le Marchand L, Kono S, Yin G, Toyomura K, Nagano J, Mizoue T, Mibu R, Tanaka M, Kakeji Y, Maehara Y, Okamura T, Ikejiri K, Futami K, Maekawa T, Yasunami Y, Takenaka K, Ichimiya H, Imaizumi N (2009) Genetic polymorphisms of CYP2E1 and risk of colorectal cancer: the Fukuoka Colorectal Cancer Study. Cancer Epidemiol Biomarkers Prev 18:235-241

Nomura F, Itoga S, Uchimoto T, Tomonaga T, Nezu M, Shimada H, Ochiai T (2003) Transcriptional activity of the tandem repeat polymorphism in the 5'-flanking region of the human CYP2E1 gene. Alcohol Clin Exp Res 27:42S-46S

Oliveri RL, Nicoletti G, Cittadella R, Manna I, Branca D, Zappia M, Gambardella A, Caracciolo M, Quattrone A (1999) Apolipoprotein E polymorphisms and Parkinson's disease. Neurosci Lett 277:83-86

Ou T, Yamakawa-Kobayashi K, Arinami T, Amemiya H, Fujiwara H, Kawata K, Saito M, Kikuchi S, Noguchi Y, Sugishita Y, Hamaguchi H (1998) 
Methylenetetrahydrofolate reductase and apolipoprotein E polymorphisms are independent risk factors for coronary heart disease in Japanese: a case-control study. Atherosclerosis 137:23-28

Papapetropoulos S, Farrer MJ, Stone JT, Milkovic NM, Ross OA, Calvo L, McQuorquodale D, Mash DC (2007) Phenotypic associations of tau and ApoE in Parkinson's disease. Neurosci Lett 414:141-144

Parsian A, Racette B, Goldsmith LJ, Perlmutter JS (2002) Parkinson's disease and apolipoprotein E: possible association with dementia but not age at onset. Genomics 79:458-461

Riedl AG, Watts PM, Jenner P, Marsden CD (1998) P450 enzymes and Parkinson's disease: the story so far. Mov Disord 13:212-220

Schmechel DE, Saunders AM, Strittmatter WJ, Crain BJ, Hulette CM, Joo SH, Pericak-Vance MA, Goldgaber D, Roses AD (1993) Increased amyloid beta-peptide deposition in cerebral cortex as a consequence of apolipoprotein $\mathrm{E}$ genotype in late-onset Alzheimer disease. Proc Natl Acad Sci U S A 90:9649-9653

Seet RC, Lee CY, Lim EC, Tan JJ, Quek AM, Chong WL, Looi WF, Huang SH, Wang H, Chan YH, Halliwell B (2010) Oxidative damage in Parkinson disease: Measurement using accurate biomarkers. Free Radic Biol Med 48:560-566

Shahabi HN, Westberg L, Melke J, Hakansson A, Belin AC, Sydow O, Olson L, Holmberg B, Nissbrandt H (2009) Cytochrome P450 2E1 gene polymorphisms/haplotypes and Parkinson's disease in a Swedish population. J Neural Transm 116:567-573 
Singh M, Khan AJ, Shah PP, Shukla R, Khanna VK, Parmar D (2008) Polymorphism in environment responsive genes and association with Parkinson disease. Mol Cell Biochem 312:131-138

Stephens EA, Taylor JA, Kaplan N, Yang CH, Hsieh LL, Lucier GW, Bell DA (1994) Ethnic variation in the CYP2E1 gene: polymorphism analysis of 695 African-Americans, European-Americans and Taiwanese. Pharmacogenetics 4:185-192

Tang G, Xie H, Xu L, Hao Y, Lin D, Ren D (2002) Genetic study of apolipoprotein E gene, alpha-1 antichymotrypsin gene in sporadic Parkinson disease. Am J Med Genet 114:446-449

Thakkinstian A, Bowe S, McEvoy M, Smith W, Attia J (2006) Association between apolipoprotein E polymorphisms and age-related macular degeneration: A HuGE review and meta-analysis. Am J Epidemiol 164:813-822

The French Parkinson's Disease Genetics Study Group (1997) Apolipoprotein E genotype in familial Parkinson's disease. J Neurol Neurosurg Psychiatry $63: 394-395$

Tsang AH, Chung KK (2009) Oxidative and nitrosative stress in Parkinson's disease. Biochim Biophys Acta 1792:643-650

Wang J, Liu Z, Chan P (2000) Lack of association between cytochrome P450 2E1 gene polymorphisms and Parkinson's disease in a Chinese population. Mov Disord $15: 1267-1269$

Watanabe J, Hayashi S, Kawajiri K (1994) Different regulation and expression of the human CYP2E1 gene due to the RsaI polymorphism in the 5'-flanking region. J 
Biochem 116:321-326

Watts PM, Riedl AG, Douek DC, Edwards RJ, Boobis AR, Jenner P, Marsden CD (1998) Co-localization of P450 enzymes in the rat substantia nigra with tyrosine hydroxylase. Neuroscience 86:511-519

Welsh-Bohmer KA, Gearing M, Saunders AM, Roses AD, Mirra S (1997) Apolipoprotein E genotypes in a neuropathological series from the Consortium to Establish a Registry for Alzheimer's Disease. Ann Neurol 42:319-325

Wu RM, Cheng CW, Chen KH, Shan DE, Kuo JW, Ho YF, Chern HD (2002) Genetic polymorphism of the CYP2E1 gene and susceptibility to Parkinson's disease in Taiwanese. J Neural Transm 109:1403-1414

Yin G, Kono S, Toyomura K, Moore MA, Nagano J, Mizoue T, Mibu R, Tanaka M, Kakeji Y, Maehara Y, Okamura T, Ikejiri K, Futami K, Yasunami Y, Maekawa T, Takenaka K, Ichimiya H, Imaizumi N (2007) Alcohol dehydrogenase and aldehyde dehydrogenase polymorphisms and colorectal cancer: the Fukuoka Colorectal Cancer Study. Cancer Sci 98:1248-1253

Yoshida T, Kato K, Fujimaki T, Yokoi K, Oguri M, Watanabe S, Metoki N, Yoshida H, Satoh K, Aoyagi Y, Nishigaki Y, Tanaka M, Nozawa Y, Kimura G, Yamada Y (2009) Association of genetic variants with chronic kidney disease in Japanese individuals. Clin J Am Soc Nephrol 4:883-890

Zhang Y, Liu Q, Duan H, Cheng J, Jiang S, Huang X, Leng S, He F, Zheng Y (2006) Association between metabolic gene polymorphisms and susceptibility to peripheral nerve damage in workers exposed to n-hexane: a preliminary study. Biomarkers 11:61-69 
Kiyohara et al. -27- 
Kiyohara et al. -28-

Table 1. Selected characteristics of patients with Parkinson's disease and controls

\begin{tabular}{|c|c|c|c|}
\hline Characteristics & $\begin{array}{l}\text { Cases } \\
(\mathrm{n}=238)\end{array}$ & $\begin{array}{l}\text { Controls } \\
(\mathrm{n}=296)\end{array}$ & P-value \\
\hline Age (year), mean (SD) & $68.5(8.68)$ & $69.7(5.63)$ & 0.06 \\
\hline \multicolumn{4}{|l|}{ Sex, n $(\%)$} \\
\hline Male & $91(38.2)$ & $114(38.5)$ & \\
\hline Female & $147(61.8)$ & $182(61.5)$ & 0.95 \\
\hline \multicolumn{4}{|l|}{ Smoking status, n (\%) } \\
\hline Current-smoker & $7(2.94)$ & $34(11.49)$ & \\
\hline Former-smoker & $57(23.9)$ & $80(27.03)$ & \\
\hline Non-smoker & $174(73.1)$ & $182(61.5)$ & $<0.0001$ \\
\hline \multicolumn{4}{|l|}{ Either home or } \\
\hline \multicolumn{4}{|c|}{ occupational pesticide use, $\mathrm{n}(\%)$} \\
\hline Positive & $122(51.3)$ & $162(54.7)$ & \\
\hline Negative & $116(48.7)$ & $134(45.3)$ & 0.43 \\
\hline \multicolumn{4}{|c|}{ Consumption of alcoholic beverages, n (\%) } \\
\hline Long-term & $35(14.7)$ & $36(12.4)$ & \\
\hline Short-term & $203(85.3)$ & $255(87.6)$ & 0.43 \\
\hline \multicolumn{4}{|c|}{ Region of residence, n (\%) } \\
\hline Fukuoka & $89(37.4)$ & $116(39.2)$ & \\
\hline Kinki & $149(62.6)$ & $180(60.8)$ & 0.67 \\
\hline
\end{tabular}

Five controls were missing drinking status data. 
Kiyohara et al. -29-

Table 2. Frequencies of $A P O E$ and $C Y P 2 E 1$ rs2864987 polymorphisms in patients with Parkinson's disease and controls

\begin{tabular}{|c|c|c|c|}
\hline & $\begin{array}{c}\text { Cases } \\
(\mathrm{n}=238), \\
\mathrm{n}(\%)\end{array}$ & $\begin{array}{c}\text { Controls* } \\
(\mathrm{n}=296), \\
\mathrm{n}(\%)\end{array}$ & P-value \\
\hline \multicolumn{4}{|l|}{$A P O E$} \\
\hline \multicolumn{4}{|l|}{ Genotypes } \\
\hline$\varepsilon 2 / \varepsilon 2$ & $1(0.42)$ & $0(0.00)$ & \\
\hline$\varepsilon 2 / \varepsilon 3$ & $21(8.82)$ & $21(7.09)$ & \\
\hline$\varepsilon 2 / \varepsilon 4$ & $7(2.94)$ & $1(0.34)$ & \\
\hline$\varepsilon 3 / \varepsilon 3$ & $164(68.9)$ & $218(73.6)$ & \\
\hline$\varepsilon 3 / \varepsilon 4$ & $43(18.1)$ & $56(18.9)$ & \\
\hline$\varepsilon 4 / \varepsilon 4$ & $2(0.84)$ & $0(0.00)$ & 0.042 \\
\hline \multicolumn{4}{|l|}{ Alleles } \\
\hline$\varepsilon 2$ & $30(6.30)$ & $22(3.72)$ & \\
\hline$\varepsilon 3$ & $392(82.4)$ & $513(86.7)$ & \\
\hline$\varepsilon 4$ & $54(11.3)$ & $57(9.63)$ & 0.084 \\
\hline \multicolumn{4}{|l|}{$\varepsilon 3$ allele status } \\
\hline None $(\varepsilon 2 / \varepsilon 2, \varepsilon 2 / \varepsilon 4, \varepsilon 4 / \varepsilon 4)$ & $10(4.20)$ & $1(0.34)$ & \\
\hline One $(\varepsilon 2 / \varepsilon 3, \varepsilon 3 / \varepsilon 4)$ & $64(26.9)$ & $77(26.0)$ & \\
\hline Two $(\varepsilon 3 / \varepsilon 3)$ & $164(68.9)$ & $218(73.6)$ & 0.007 \\
\hline \multicolumn{4}{|l|}{$\varepsilon 2$ allele status } \\
\hline None $(\varepsilon 3 / \varepsilon 3, \varepsilon 3 / \varepsilon 4, \varepsilon 4 / \varepsilon 4)$ & $209(87.8)$ & $274(92.6)$ & \\
\hline At least one allele $(\varepsilon 2 / \varepsilon 2, \varepsilon 2 / \varepsilon 3, \varepsilon 2 / \varepsilon 4)$ & $29(12.2)$ & $22(7.43)$ & 0.063 \\
\hline \multicolumn{4}{|l|}{$\varepsilon 4$ allele status } \\
\hline None $(\varepsilon 2 / \varepsilon 2, \varepsilon 2 / \varepsilon 3, \varepsilon 3 / \varepsilon 3)$ & $186(78.2)$ & $239(80.7)$ & \\
\hline At least one allele $(\varepsilon 2 / \varepsilon 4, \varepsilon 3 / \varepsilon 4, \varepsilon 4 / \varepsilon 4)$ & $52(21.8)$ & $57(19.3)$ & 0.460 \\
\hline \multicolumn{4}{|l|}{ CYP2E1 rs 2864987} \\
\hline \multicolumn{4}{|l|}{ Genotypes } \\
\hline $\mathrm{TT}$ & $118(49.6)$ & $134(45.3)$ & \\
\hline $\mathrm{TC}$ & $100(42.0)$ & $135(45.6)$ & \\
\hline
\end{tabular}


Kiyohara et al. -30-

$\mathrm{CC}$

$20(8.40) \quad 27(9.12) \quad 0.612$

Alleles

$\mathrm{T}$

$336(70.6) \quad 403(68.1)$

C

$140(29.4) \quad 189(31.9) \quad 0.376$

Five controls were missing drinking status data.

*Adjusted for age, sex, region, smoking status, drinking status and pesticide exposure. 
Kiyohara et al. -31-

Table 3. Associations of $A P O E$ and CYP2E1 rs2864987 polymorphisms, and Parkinson's disease

\begin{tabular}{|c|c|c|}
\hline \multirow[b]{2}{*}{ Polymorphism } & \multicolumn{2}{|c|}{ OR $(95 \% \mathrm{CI})$} \\
\hline & Crude & Adjusted* \\
\hline \multicolumn{3}{|l|}{$A P O E$} \\
\hline \multicolumn{3}{|l|}{ Genotype } \\
\hline$\varepsilon 2 / \varepsilon 2$ & - & - \\
\hline$\varepsilon 2 / \varepsilon 3$ & $1.33(0.70-2.52)$ & $1.26(0.65-2.41)$ \\
\hline$\varepsilon 2 / \varepsilon 4$ & $9.30(1.13-76.4)$ & $9.50(1.12-80.6)$ \\
\hline$\varepsilon 3 / \varepsilon 3$ & 1.0 (ref.) & 1.0 (ref.) \\
\hline$\varepsilon 3 / \varepsilon 4$ & $1.02(0.65-1.59)$ & $0.98(0.62-1.55)$ \\
\hline$\varepsilon 4 / \varepsilon 4$ & - & - \\
\hline \multicolumn{3}{|l|}{$\varepsilon 3$ allele status } \\
\hline None $(\varepsilon 2 / \varepsilon 2, \varepsilon 2 / \varepsilon 4, \varepsilon 4 / \varepsilon 4)$ & 1.0 (ref.) & 1.0 (ref.) \\
\hline One $(\varepsilon 2 / \varepsilon 3, \varepsilon 3 / \varepsilon 4)$ & $0.08(0.01-0.67)$ & $0.08(0.01-0.66)$ \\
\hline Two $(\varepsilon 3 / \varepsilon 3)$ & $0.08(0.01-0.59)$ & $0.08(0.01-0.61)$ \\
\hline At least one allele $(2 / \varepsilon 3, \varepsilon 3 / \varepsilon 3, \varepsilon 3 / \varepsilon 4)$ & $0.08(0.01-0.61)$ & $0.08(0.01-0.62)$ \\
\hline \multicolumn{3}{|l|}{$\varepsilon 2$ allele status } \\
\hline None $(\varepsilon 3 / \varepsilon 3, \varepsilon 3 / \varepsilon 4, \varepsilon 4 / \varepsilon 4)$ & 1.0 (ref.) & 1.0 (ref.) \\
\hline At least one allele $(\varepsilon 2 / \varepsilon 2, \varepsilon 2 / \varepsilon 3, \varepsilon 2 / \varepsilon 4)$ & $1.73(0.97-3.09)$ & $1.66(0.91-3.00)$ \\
\hline \multicolumn{3}{|l|}{$\varepsilon 4$ allele status } \\
\hline None $(\varepsilon 2 / \varepsilon 2, \varepsilon 2 / \varepsilon 3, \varepsilon 3 / \varepsilon 3)$ & 1.0 (ref.) & 1.0 (ref) \\
\hline At least one allele $(\varepsilon 2 / \varepsilon 4, \varepsilon 3 / \varepsilon 4, \varepsilon 4 / \varepsilon 4)$ & $1.17(0.77-1.79)$ & $1.14(0.74-1.78)$ \\
\hline \multicolumn{3}{|l|}{ CYP2E1 rs2864987 } \\
\hline \multicolumn{3}{|l|}{ Genotype } \\
\hline $\mathrm{TT}$ & 1.0 (ref.) & 1.0 (ref.) \\
\hline $\mathrm{TC}$ & $0.84(0.59-1.20)$ & $0.77(0.53-1.11)$ \\
\hline $\mathrm{CC}$ & $0.84(0.45-1.58)$ & $0.79(0.41-1.51)$ \\
\hline At least one $\mathrm{C}$ allele (TC, CC) & $0.84(0.60-1.18)$ & $0.77(0.54-1.10)$ \\
\hline
\end{tabular}

OR, odds ratio; $95 \% \mathrm{CI}, 95 \%$ confidence interval

Five controls were missing drinking status data.

*Adjusted for age, sex, region, smoking status, drinking status and pesticide exposure. 
Table 4. Interaction between alcohol consumption and CYP2E1 rs2864987 genotypes

\begin{tabular}{|c|c|c|c|c|c|c|}
\hline \multirow{2}{*}{ Genotype } & \multirow{2}{*}{ Drinking status* } & \multirow{2}{*}{$\begin{array}{l}\text { Number of } \\
\text { cases/controls** }\end{array}$} & \multicolumn{4}{|c|}{ OR $(95 \% \mathrm{CI})$} \\
\hline & & & Crude & P-value & Adjusted $\dagger$ & P-value \\
\hline $\mathrm{TC}+\mathrm{CC}$ & Short-term & $103 / 139$ & 1.0 & & 1.0 & \\
\hline $\mathrm{TT}$ & Short-term & $100 / 116$ & $1.04(0.53-2.06)$ & 0.904 & $1.25(0.85-1.82)$ & 0.256 \\
\hline $\mathrm{TC}+\mathrm{CC}$ & Long-term & $17 / 22$ & $1.16(0.80-1.68)$ & 0.422 & $1.36(0.64-2.88)$ & 0.421 \\
\hline TT & Long-term & $18 / 14$ & $1.74(0.82-3.65)$ & 0.146 & $2.24(1.01-4.95)$ & 0.046 \\
\hline \multicolumn{3}{|c|}{ Multiplicative interaction measure } & $1.43(0.52-3.94)$ & 0.488 & $1.32(0.47-3.74)$ & 0.600 \\
\hline \multicolumn{7}{|c|}{ Additive interaction measure } \\
\hline \multicolumn{3}{|c|}{ Relative excess due to interaction } & $0.51(-0.96-1.99)$ & 0.498 & $0.63(-1.31-2.57)$ & 0.524 \\
\hline \multicolumn{3}{|c|}{ Attributable proportion due to interaction } & $0.29(-0.38-0.95)$ & 0.393 & $0.27(-0.41-0.95)$ & 0.436 \\
\hline \multicolumn{3}{|c|}{ Synergy index } & $2.79(0.09-84.2)$ & 0.557 & $1.90(0.26-13.8)$ & 0.526 \\
\hline
\end{tabular}

OR, odds ratio; $95 \% \mathrm{CI}, 95 \%$ confidence interval

* Long-term, continuing drinking for $\geq 50$ years; short-term, continuing drinking for $<50$ years

** Five controls were missing drinking status data.

$\dagger$ Adjusted for age sex, region, smoking status and pesticide exposure. 